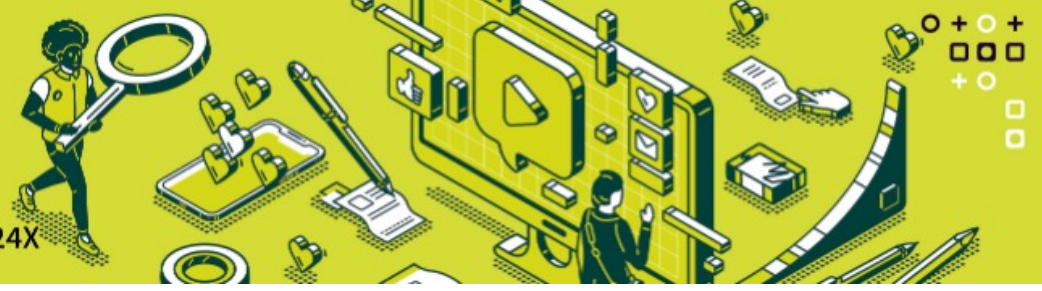

\title{
DESIGN THINKING APLICADO A INTERAÇÃO DE ELEMENTOS COMUNICACIONAIS EM
}

Design Thinking applied to the interaction of communicational elements in social networks

${ }^{1}$ Jessica Bentes Galdino; ${ }^{2}$ Ana Clara Almeida e Silva Bouzon; ${ }^{3}$ Ana Luiza Marques de Souza; ${ }^{4}$ Sheila Cordeiro Mota.

1Universidade Federal do Amazonas - jessica.bgaldino@gmail.com

2Universidade Federal do Amazonas - acbouzon@gmail.com

3Universidade Federal do Amazonas - marquesdesouzaanaluiza@gmail.com

4Universidade Federal do Amazonas - sheimota@ufam.edu.br

RESUMO: Este artigo aborda um estudo guiado pelo método Design Thinking, objetivando entender a interação do usuário com elementos comunicacionais de redes sociais para obter uma análise a partir do relato da interação e experiência do usuário. Estas análises poderão melhorar a experiência do usuário, do ponto de vista das interações sociais e técnicas, cujos atributos serão estratégicos para possíveis inovações na interface das redes sociais estudadas. O método utilizado traz uma concepção que objetiva gerar conhecimento para aplicação prática e dirigida, sendo também descritiva, pois analisa os dados de forma indutiva, possuindo uma relação qualitativa. Sendo assim, foi mapeada a percepção do usuário a partir de um questionário online, buscando entender o perfil dos usuários de redes sociais, a partir de análises bibliográficas e de estudo de caso. Os resultados obtidos apresentam um levantamento da percepção de um determinado grupo de usuários, resultante da etapa inicial do Design Thinking, contribuindo para melhorias, podendo tornar essa ferramenta sócio aplicada mais eficiente.

Palavras-chave: Design Thinking, Interação, Redes Sociais

ABSTRACT: This article presents a study guided by the Design Thinking method, aiming to understand the user's interaction with communicational elements of social networks to obtain an analysis from the interaction and user experience report. These analyzes may serve as a guide to improve the user experience, from the point of view of social and technical interaction, whose attributes will be strategic for possible innovations within the studied social networks' interfaces. The method used for this study aims to generate knowledge for practical and directed application, being also descriptive, as it analyzes the data inductively, having a qualitative relationship. Therefore, the user's perception was mapped, based on an online questionnaire, seeking to understand the profile of social networks' users, based on bibliographic analyzes and a case study. The results obtained present a survey of the users' perceptions, resulting from the initial stage of Design Thinking, contributing to possible improvements that can make this social applied tool more efficient.

Keywords: Design Thinking, Interaction, Social Networks

RESUMEN: Este artículo presenta un estudio de Design Thinking, que objetiva comprender la interacción del usuario con elementos comunicacionales de redes sociales para obtener una análisis a partir de la interacción y experiencia del usuario. Estos análisis pueden mejorar la experiencia del usuario con las interacciones sociales y técnicas, cuyos atributos serán estratégicos para posibles innovaciones en la interfaz de las redes sociales estudiadas. El método utilizado trae una concepción que tiene como objetivo generar conocimiento para su aplicación práctica y dirigida, siendo también descriptivo, porque analiza los datos de manera inductiva, teniendo una relación cualitativa. Han sido realizados mapeos de la percepción del usuario con un cuestionario online, comprendendo el perfil de los usuarios de redes sociales, a partir de análisis bibliográficos y un caso de estudio. Los resultados obtenidos presentan una encuesta de la percepción de un determinado grupo de usuarios, resultante de la etapa inicial del Design Thinking, contribuyendo com mejoras para ser más eficiente.

Palabra clave: Design Thinking, Interacción, Redes sociales 


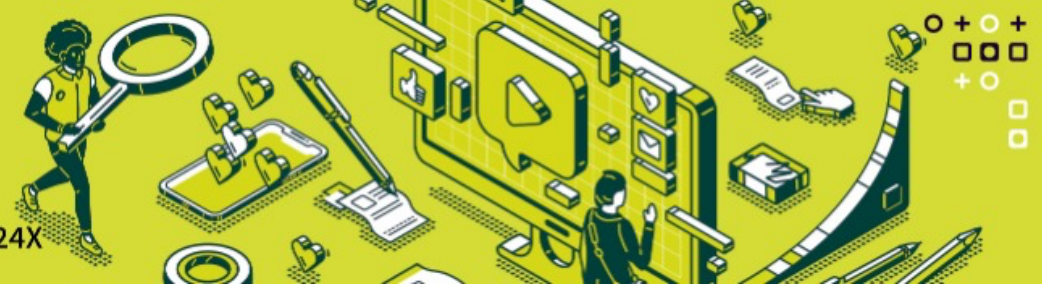

\section{INTRODUÇÃO}

\subsection{DESIGN DE INTERAÇÃO}

O Design de Interação, por ser uma área recentemente adicionada aos estudos de Design, não possui uma conceituação unânime entre seus estudiosos. Cooper (2007), Löwgren (2002) e Winograd (1997; 2005), entre outros autores, se dedicaram a propor definições do termo, e embora tenham pequenas disparidades, diz genericamente, que é a área na qual se fundamenta a interação em artefatos digitais. Segundo Gonzatto (2014, pág. 100), "uma constante entre essas definições é a caracterização de seu foco nos computadores (sistemas digitais, interfaces interativas) como objeto de interesse".

Apesar de focar nas interfaces digitais, o designer de interação deve considerar também as experiências de usuário que ocorrerão dentro do sistema por ele criado. Assim, o designer se propõe a criar ferramentas que, no produto, irão servir como inúmeras formas de um usuário interagir com a interface, resultando em experiências e reações diferentes. Ou seja, é necessário que usuário esteja em foco em se tratando da criação de novos meios digitais. Simões e Valente (2018) apresentam evidências sobre esse pensamento, esclarecendo como fundamental, que as mídias digitais sejam criadas com foco nos interesses e experiências significativas para seus usuários. Em uma interface interativa, a experiência do usuário que irá ditar o quão eficiente é o sistema, em questão de funcionalidade, agradabilidade e estética. É importante também pontuar que toda interface interativa acarretará uma experiência, seja esta proposital ou involuntária, positiva ou negativa. Por isso, ao se criar uma interface, deve haver um planejamento com base em análises prévias destas experiências, ainda que não seja possível prever todas elas, para minimizar a ocorrência de experiências negativas (ELLWANGER, 2013).

Com o aumento do mercado das tecnologias de tablets, houve uma atualização de certas atividades cotidianas, como a leitura, que se tornou algo digital por conta desses dispositivos móveis. Esse novo hábito obrigou os principais meios de mídia e comunicação a se atualizarem e se adaptarem a tal inovação, com isso os tradicionais jornais em papéis foram caindo em desuso e gerando uma necessidade de se reinventar.

A partir disso houve um grande interesse em conhecer melhor e estudar de forma mais profunda os elementos de interface gestual para melhor adaptação e usabilidade dos usuários. Segundo De Souza (2005) a interface é vista como uma mensagem enviada pelo designer ao usuário, ou seja, o designer é o responsável por projetar e desenvolver os elementos de interação humanocomputador, estabelecendo uma comunicação e facilitando a compreensão do usuário, para isso é necessário a utilização de elementos representativos universais e que sejam de fácil interpretação. Foram levados em consideração também para esse estudo elementos como a taxonomia e ergonomia dos gestos a fim de entender e mapear os gestos humanos na utilização dessas tecnologias.

Os Ambientes Virtuais de Aprendizagem (AVA), estão ganhando cada vez mais uma maior visibilidade, graças ao avanço das tecnologias e assim facilitando a interação entre alunos e professores. Esses softwares educacionais são alvos de constantes pesquisas devido à necessidade de entregar um design de qualidade e facilidade de manuseio, esses ambientes virtuais são utilizados nos processos de ensino e aprendizado por tanto a utilização de símbolos autoexplicativos e um sistema de significação para inclusão de todos torna-se indispensável.

Um aspecto pouco estudado, porém, determinante para a interpretação desses símbolos, é o contexto cultural, pois o que pode ser entendido de forma clara para um usuário pode não ser para outro e por isso a importância de o designer considerar esse fator. Rosa (2015 apud Matos, p.1, 2008) "os usuários não chegam com as mentes vazias frente as telas dos computadores, uma vez que trazem consigo um sistema de significação construído sócio culturalmente", por isso a relação entre os usuários e a interface deve ser cada vez mais descomplicada e trazer uma maior usabilidade por meio dos ícones, índices e símbolos. 


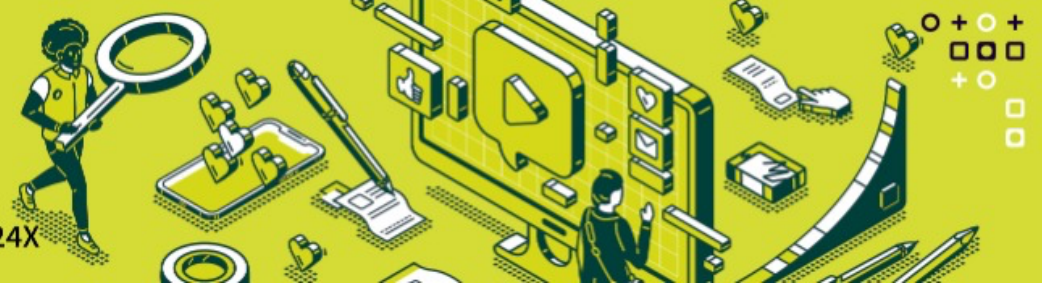

De acordo com Winogard e Flores (1987 apud Gonzatto, 2014, p.155), 'O design inclui a geração de novas possibilidades', e isso é notado principalmente no design de interação, pois os usuários, mesmo não podendo fazer alterações diretamente no código fonte do site ou aplicativo com que interagem, geram mudanças quando se apropriam e dão novos significados e usos às ferramentas já existentes nestes sistemas, ganhando novas funções além das originalmente planejadas pelos designers e desenvolvedores, sendo incorporadas oficialmente na plataforma. Segundo Simão (2003), o design de interação exige que o profissional que projeta interfaces interativas tenha conhecimento de várias áreas interdisciplinares e práticas de design, para que possa considerar elementos que afetam a experiência do usuário e a performance do software utilizado, e conseguir se comunicar com a equipe multidisciplinar para a elaboração dos projetos de interfaces. Design de interação procura melhorar o meio pelo qual as pessoas se comunicam e interagem. De acordo com Silva (2011), quando uma interface é mal projetada e leva o interagente a errar, ele não entende como falha no sistema, e sim como culpa sua. Isso causa frustração e uma experiência ruim que acaba afastando o usuário da interface em questão e até de outras similares, pois o contato com esse app anterior influencia tanto positivamente quanto negativamente experiências atuais e futuras.

O designer tem o objetivo de atingir o equilíbrio entre usabilidade, através de eficiência, e experiência do usuário, ou seja, como o usuário se sente ao interagir com o sistema. Para atingir esses resultados, uma interface deve ser agradável, tanto de manusear quanto esteticamente. Deve ser satisfatório, divertido e gratificante. Para garantir que as interfaces sejam agradáveis e fáceis de manipular existe o design de interação.

Para isso, é preciso entender o usuário e como ele utilizará o produto, para que se possa então estipular os principais parâmetros que afetarão o desenvolvimento do produto e, futuramente, a experiência deste usuário. Faz-se necessário que os projetos de produtos interativos sejam planejados por uma equipe multidisciplinar, pois como cita Santos (2013, p.154) "A utilização de especialidades diferentes (Psicologia, Engenharia, Informática, etc.) em um mesmo projeto traz interpretações diversas sobre o que está sendo desenvolvido, aumentando a quantidade de ideias, métodos e soluções criativas para o projeto.", e nessa multidisciplinaridade um profissional cobre os "pontos cegos" projetuais dos outros, gerando soluções mais completas que cumpram melhor seus objetivos. O processo projetual do design de interação se dá através de cinco atividades, apontadas por Preece, Rogers \& Sharp (2005 apud Santos, 2013, p.154):

- Identificar necessidades;

- Propor soluções para o problema;

- Desenvolver designs alternativos e que preencham as necessidades do item anterior;

- Construir protótipos interativos dos designs propostos;

- Avaliar o que está sendo construído durante o seu desenvolvimento.

O projeto de uma interface interativa ainda deve, segundo Santos (2013), ser focado em atender critérios que garantam a boa usabilidade e experiência do usuário, seguindo princípios básicos do Design, como os estipulados por Norman (2006 apud Santos, 2013, p.156):

- Visibilidade - As funções do sistema deixam claro aos usuários o que eles devem fazer?

- Feedback - Que retorno o usuário recebe após suas ações?

- Restrições - Como estão sinalizadas, para o usuário, as áreas e funções que ele pode utilizar e quais estão desativadas?

- Mapeamento - Existe uma relação lógica entre os controles e seus efeitos?

- Consistência - As interfaces foram projetadas para que seus elementos realizem operações comuns entre si?

- Affordance - O produto tem uma característica que permite às pessoas saber como usá-lo?

Outros pontos a serem levados em consideração ao projetar uma interface são: estar passível de aprimoramentos e garantir que o produto não se tornará obsoleto por não seguir as tendências e as novas necessidades dos usuários, garantir a boa usabilidade, utilização de linguagem clara e comum, ser intuitivo, prever e evitar falhas. 


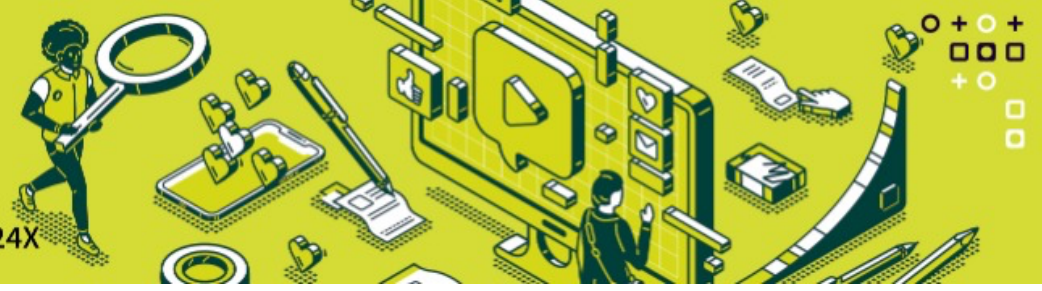

Considerando a interação do usuário com qualquer meio de interação de que faça uso para sua comunicação, torna-se importante ressaltar que a área do Design faz uso de análises fundamentadas em métodos para propor melhorias constantes em projetos de interface. Dessa forma, esse estudo também buscou entender o universo estudado para criar mais elementos que possam ser aplicadas a essa difusão de entendimento. Portanto, torna-se essencial orientações científicas acerca do prisma deste estudo, como por exemplo as redes sociais e sua relação desde o ponto de vista do Design emocional e UX (User Experience), consolidando um compilado de informações essenciais para orientar.

\subsection{REDES SOCIAIS, DESIGN EMOCIONAL E EXPERIÊNCIA DO USUÁRIO}

As redes sociais podem ser usadas para diversos fins, mas têm como objetivo principal promover a interação e a comunicação entre indivíduos, e para isso algumas necessidades precisam ser atendidas. Os designers e programadores precisam garantir que haja uma boa interação entre o usuário e a interface, para que a plataforma seja fácil de usar e entender, se tornando uma boa experiência para o usuário e facilitando a interação deste com outras pessoas.

Durante o uso das redes sociais, os usuários se apropriam das ferramentas disponíveis e dão a elas novas funções e significados, e é preciso que o site ou aplicativo se adeque a esses novos usos criados pelos próprios usuários, como é o caso do Twitter, que já passou por uma série de adequações que não foram originalmente planejadas pelos designers e desenvolvedores, mas que surgiram a partir dos usuários e foram incorporadas não só pelo Twitter, mas também se popularizaram em outras redes sociais, como é o caso do uso de hashtags, como destacado por Polino (2015) "[...] usuários de outros sites redes sociais só passaram a utilizar as hashtags e conhecer sua função depois de ser inserida no Twitter pelos seus desenvolvedores a partir da apropriação dos usuários." (POLINO, 2015, p.9).

Outras mudanças geradas baseadas no uso dado pelos usuários ao Twitter são o aumento do limite de caracteres por tweet de 140 para 280, inclusão da possibilidade de comentar um tweet ao retweetar (compartilhar), a possibilidade de inclusão de imagens nos tweets e a mudança da pergunta feita ao se criar um novo tweet, que já foram "compor um novo tweet" e "o que você está pensando?", e hoje é "o que está acontecendo?", refletindo a mudança entre os usos atribuídos, como descrito por Polino (2015):

Observando essas simples frases, percebe-se que o sistema já foi mais voltado para a publicização dos acontecimentos sobre a vida do usuário e para as publicações de mensagens contando suas vontades, desejos, etc., e atualmente ele pergunta "o que está acontecendo?", induzindo o usuário a ser um "repórter" dos acontecimentos do seu bairro, do seu dia a dia, utilizar esse espaço para contar fatos, criticar e debater sobre assuntos estando eles dentro ou fora da vida cotidiana do usuário. (POLINO, 2015, p.10)

A experiência do usuário é um elemento de caracterização do Design no âmbito das redes sociais, sendo algo intersubjetivo devido a interação IHC (interação humano-computador). Günther (2013), fala sobre as dificuldades encontradas pelos usuários, tratando também da importância do design como informação e como o profissional da área tem influência a ponto de conseguir manipular aspectos sensoriais, conteúdos e até mesmo as experiências do usuário, exemplificado pelas redes sociais.

A funcionalidade dessas redes sociais acontece devido a uma boa facilidade de uso, consequentemente uma boa usabilidade, representando um aspecto de avanços bem-sucedidos de projetos nessa esfera, que deixaram de ser um diferencial e passaram a ser uma condição, aumentando o nível das práticas profissionais dos designers. Além desses elementos chaves (funcionalidade e usabilidade), o aspecto estético também é fundamental para gerar informação, 


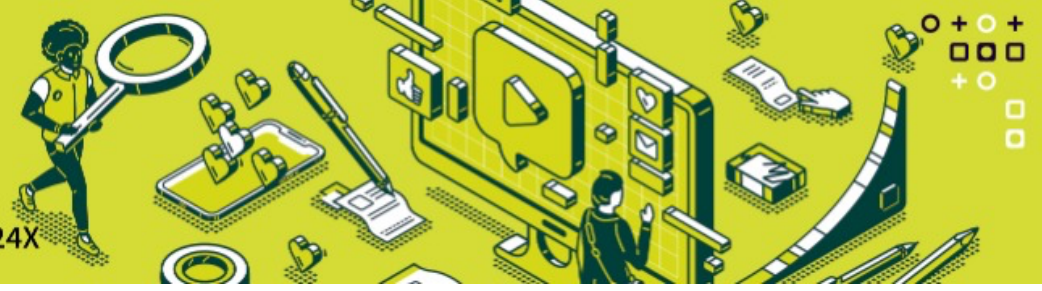

seja através das percepções ou das sensações, com o uso de componentes da comunicação visual como linhas, formas e cores. De acordo com Norman (2008, apud Günther e Triska 2013) "o estético está subordinado ao aspecto emocional, ou é compreendido como tal".

De tal maneira como os aspectos cognitivos, as emoções exercem importante função quanto à tomada de decisões do usuário, já que uma pessoa escolhe determinado produto não somente com base em sua forma e função, mas também considera o significado deste produto para si (HACK e SANTOS, 2010). Dados os aspectos emocionais desse processo, pode-se então compreender que em uma interface de interação entre pessoas é fundamental para o usuário ter uma experiência positiva, que o leve à imersão completa na interface, de modo a disfarçar eventuais falhas do sistema, como citam Damle e Smith (apud SUWA \& TVERSKY, 1997)

\footnotetext{
"[...] é fundamental desenvolver interfaces que despertem sensações positivas nas pessoas, de maneira que esse sentimento as leve a experimentar um momento de imersão onde até mesmo os mecanismos utilizados para essa tarefa pareçam não existir, como o teclado, o mouse e o monitor.". Damle e Smith (citando SUWA \& TVERSKY, 1997, p. 420)
}

Design emocional é uma forma de design centrado no usuário que utiliza a tecnologia e suas ferramentas para gerar emoções intencionais e bem definidas através das experiências e da interação do utilizador com o produto (Fonseca et al., 2015), e utiliza da combinação de recursos estéticos e funcionais para cativar o usuário através de suas respostas emocionais. Uma má experiência com um produto leva o usuário a ter emoções negativas e evitar o contato com aquele produto novamente, enquanto uma boa experiência levará a emoções positivas, que manterão o usuário do produto satisfeito e fidelizado.

Segundo Reynolds et al. (2008 apud Fonseca et al., 2015, p.147), no uso de recursos visuais, por exemplo, textos e imagens estáticas não são tão interessantes ou estimulantes para o usuário quanto animações e vídeos, então o mesmo conteúdo apresentado de formas diferentes também será recebido e interpretado de formas diferentes, dependendo da resposta emocional do usuário. O aumento da satisfação pode levar a facilitação do processo cognitivo, melhorando o desempenho do usuário em relação ao uso do produto ou interface. Também vale comentar que, diante de novos desafios projetuais, surgem novos métodos que possibilitam ao designer desenvolver uma amplitude maior de elementos que consigam conectar as demandas de serviço de Design com o perfil de usuário correspondente.

O método do Design Thinking possui algumas técnicas que possibilitam tal relação. O Design Thinking, ou em português chamado "pensamento de designer", de modo geral é uma forma diferente de pensar que lança mão de métodos e habilidades desenvolvidas pelo próprio designer, e que é aplicado por grandes empreendedores ao longo dos últimos anos para resolver problemas de projeto de ordem mais abstrata.

A estrutura do Design Thinking se organiza basicamente em três etapas, cada uma delas com procedimentos específicos. Este estudo abordou a primeira etapa, limitando-se aos objetivos da pesquisa, ou seja, realizou um mapeamento do perfil dos usuários das redes sociais, dentro de um determinado escopo e síntese amostral.

\section{METODOLOGIA}

\subsection{O MÉTODO DO DESIGN THINKING}

O Design Thinking se baseia na colaboração entre profissionais de múltiplas disciplinas, uma vez que aborda conceitos além do Design, focando também na engenharia, arte e ciências sociais. 0 


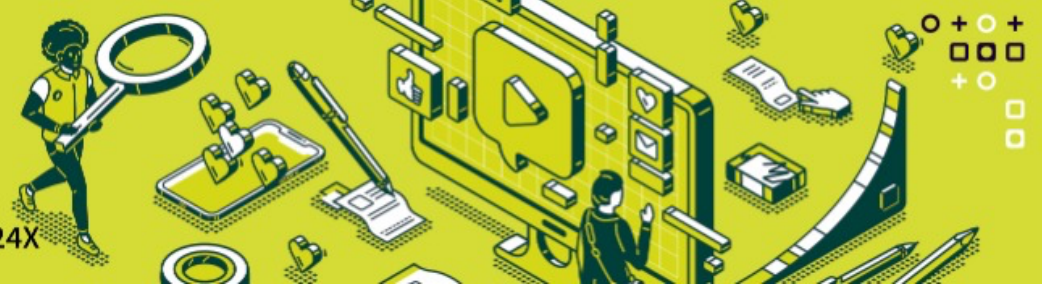

objetivo desse meio é criar e avaliar protótipos a partir da compreensão das necessidades do usuário, a fim de gerar artefatos inovadores em relação à experiência dos seus usuários.

Ainda, o Design Thinking é fundamentado pelo Design Centrado no Ser Humano (DCH), o que revela seu caráter humanista, pois o DCH se preocupa com o modo como os indivíduos veem, interpretam, e convivem com artefatos (KIPPERNDORFF, 2000, apud CAVALCANTI, 2014, pág. 3). O Design Thinking é um método inovador, que ressignifica a maneira com que produtos e serviços são criados, pois considera todos os aspectos - emocionais, cognitivos, estéticos e funcionais envolvidos na rede complexa dos sistemas interativos para que façam sentido aos usuários (ELLWANGER, 2013). Fica claro também que o fato deste método levar o nome do profissional (designer) não significa que pessoas formadas em áreas divergentes não possam utilizá-lo por falta de conhecimento acadêmico/técnico. Qualquer pessoa, seja ele da área ou não, possui percepção para ser um design thinker.

O Método do Design Thinking, proposto por Brown (2010), contempla alguns procedimentos em sua etapa inicial. Uma delas se denomina "Brief", também chamada de "Imersão" pelos autores brasileiros. É valido observar novamente que não se torna obrigatório seguir as etapas desse método na ordem que são mencionadas. A figura 01, apresentada por Viana (2012) destaca as fases do método, demonstrando uma versatilidade cíclica, uma vez que é possível voltar às etapas de acordo com a análise dos resultados entre elas.

Figura 01: Representação das etapas do processo de Design Thinking

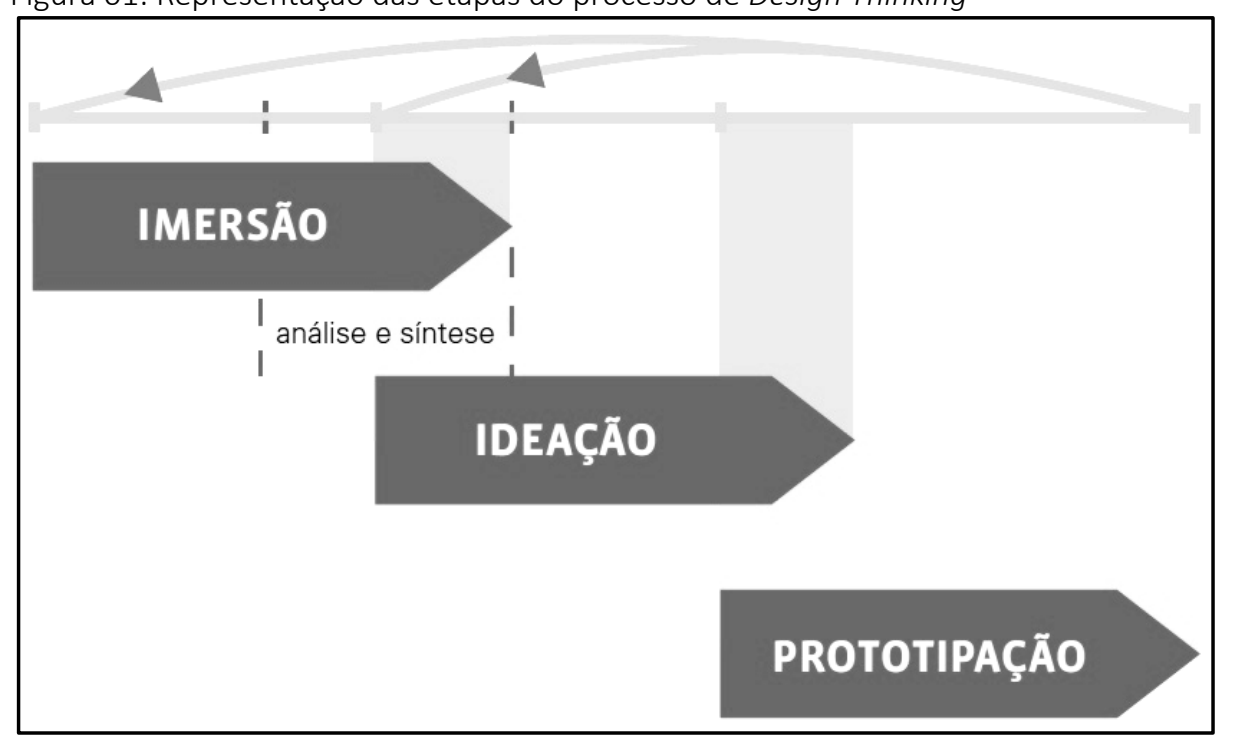

Fonte: Viana (2012)

\subsection{FerRAMENTAS dA IMERSÃo do Design ThINKING}

Para entender os temas de projetos a serem desenvolvidos, foram criadas, segundo Vianna (2012), ferramentas que auxiliam a aproximação do projetista com a empresa no propósito de identificar possíveis problemáticas. As principais ferramentas durante a fase da Imersão Preliminar são as seguintes:

a) Reenquadramento: examinar problemas não resolvidos sob diferentes perspectivas, permitindo desconstruir crenças e suposições dos atores (stakeholders) e quebrar seus padrões de pensamento, ajudando-os a mudar paradigmas e dar o primeiro passo para alcançar soluções inovadoras.

b) Pesquisa Exploratória: auxilia no entendimento do contexto a ser trabalhado e fornece insumos para a definição dos perfis de usuários, atores e ambientes ou momentos do 
ciclo de vida do produto/serviço que serão explorados na Imersão em Profundidade. Ajuda também na elaboração dos temas a serem investigados na Pesquisa Desk.

c) Pesquisa Desk: busca de informações sobre o tema do projeto em fontes diversas (websites, livros, revistas, blogs, artigos, entre outros).

E durante a fase de Imersão em Profundidade são realizadas:

a) Entrevistas: conversa com o entrevistado onde procura-se obter informações que permeiem o assunto pesquisado através de perguntas, cartões de evocação cultural e outras técnicas.

b) Cadernos de sensibilização: utilizado para coletar dados do usuário com o mínimo de interferência sobre suas ações, ou quando a questão investigada se desenrola de forma intermitente ou dentro de um longo período. Ao contrário de uma abordagem de observação direta e presencial, esta técnica permite que o próprio usuário faça o relato de suas atividades, no contexto de seu dia a dia.

c) Sessões generativas: encontro no qual se convida os usuários para que dividam suas experiências e realizem juntos atividades nas quais expõem suas visões sobre os temas do projeto. Visa entender o que sabem, sentem e sonham, muitas vezes de maneira tácita e latente.

d) Um dia na vida: simulação, por parte do pesquisador, da vida de uma pessoa ou situação estudada. Ou seja, membros da equipe de projeto assumem o papel do usuário e passam um período agindo sob um diferente ponto de vista e interagindo com os contextos e pessoas com os quais se estaria confrontado no dia a dia.

e) Sombra: acompanhamento do usuário ao longo de um período de tempo que inclua sua interação com o produto ou serviço que está sendo analisado. Enquanto "sombra", o pesquisador não deve interferir na ação do usuário, apenas observá-lo.

Nesta pesquisa, para a fase de Imersão em Profundidade, foi feita a elaboração da entrevista, veiculada por meio do Formulários do Google, que possui uma caracterização indutiva sobre aspectos que possuem relação com o entendimento sobre percepções e pensamentos observados a partir dos estudos na pesquisa exploratória de base teórica.

A entrevista possuiu 3 (três) blocos conceituais, abordando: 1) Aspecto tecnológico; 2) Aspecto Ergonômico informacional; 3) Aspecto Sócio/Cultural.

Considerando a hegemonia da área de conhecimentos dos expertos entrevistados, serão agrupados em um único bloco os aspectos tecnológicos, ergonômicos e socioculturais.

O convite de participação para a entrevista foi veiculado por meio de um anúncio (figura 02), com o qual o grupo apresentava os propósitos da pesquisa, assim como o link de acesso ao formulário. Os participantes surgiram a partir de indicações em grupos próprios dos alunos envolvidos.

Figura 02: Anúncio de apresentação dos objetivos da pesquisa 


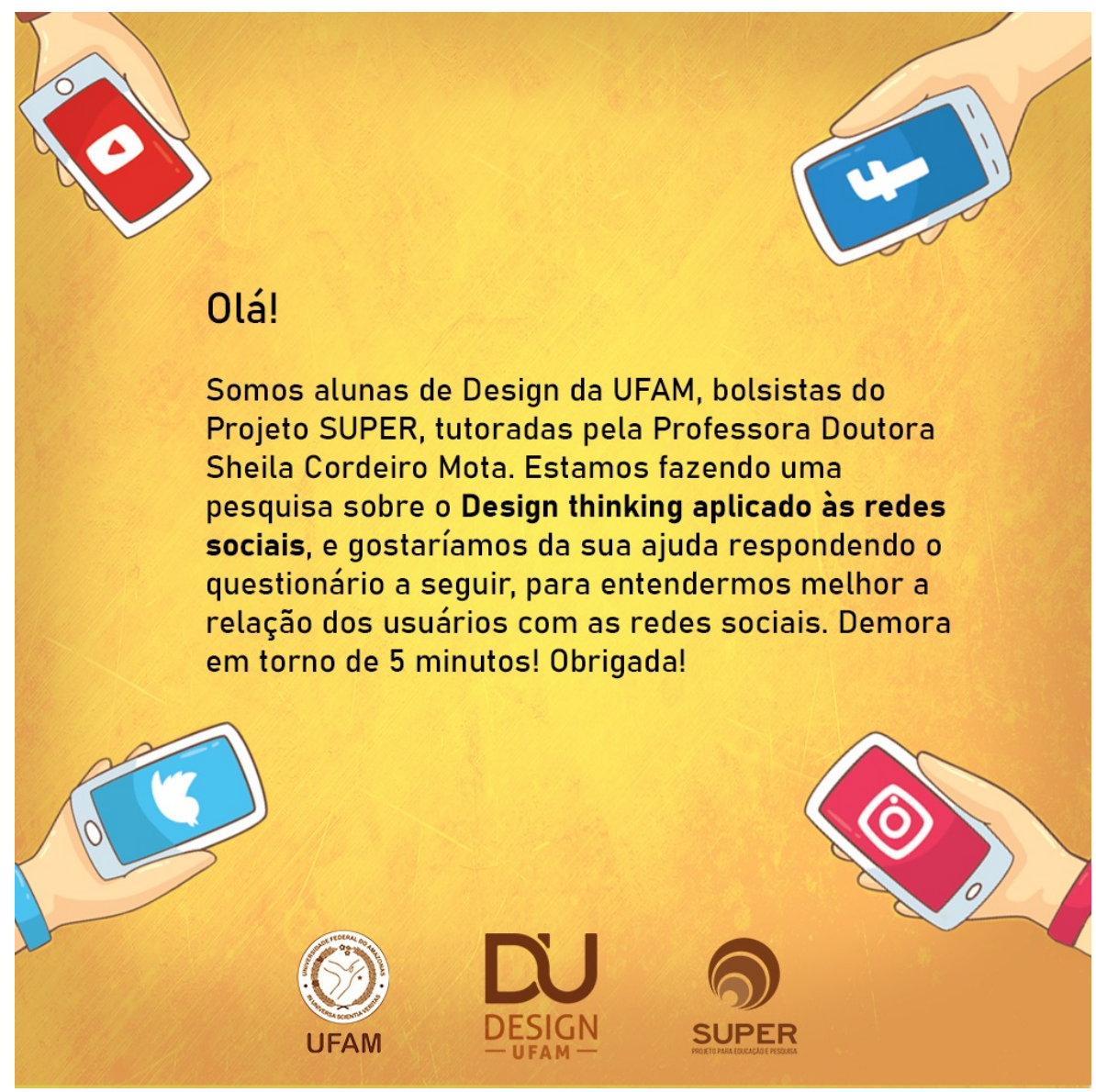

Fonte: As autoras (2021)

A abordagem do Design Thinking utilizada nesse estudo lançou mão da primeira etapa, definida como Imersão Preliminar, que tem como principal finalidade encontrar o princípio do problema, seja na visão da empresa ou até mesmo do próprio cliente ou usuário. Segundo Vianna (2012) recomenda-se a realização de reuniões de alinhamento estratégico entre a equipe que conduzirá o projeto e profissionais da empresa contratante, durante as quais é realizado o processo de reenquadramento. A Imersão Preliminar, portanto, tem como finalidade definir o escopo do projeto e suas fronteiras, além de identificar os perfis de usuários e outros atores-chave que deverão ser abordados. Nesta fase, é possível também levantar as áreas de interesse a serem exploradas de forma a fornecer insumos para a elaboração dos temas que serão investigados na Imersão em Profundidade. (VIANNA, ET AL, 2012, p 22)

Neste caso, foram realizadas reuniões da equipe de pesquisa, por meio remoto, propondo uma análise mais geral sobre o estudo de caso, definindo-se assim sua organização estrutural, cronograma, métodos de análise teórico e prático, assim como o escopo da entrevista, ambiente e amostra de participantes da pesquisa. A estrutura desta pesquisa foi então coordenada a partir das subdivisões mostradas no quadro 1 , a seguir: 


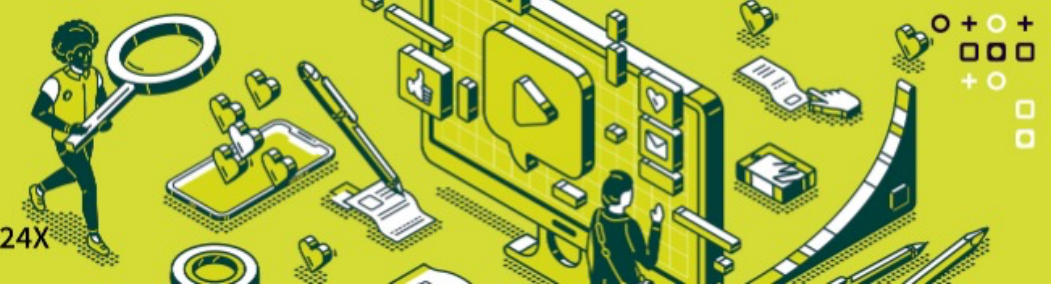

Quadro 1: Estrutura da pesquisa

\begin{tabular}{|c|c|}
\hline \multirow{4}{*}{$\begin{array}{l}\text { Detalhamento } r \\
\text { subdivisão da } \\
\text { etapa }\end{array}$} & Introdução/Resumo; \\
\hline & $\begin{array}{l}\text { Contextualização do tema; } \\
\text { Características da área de estudo; }\end{array}$ \\
\hline & $\begin{array}{l}\text { Justificativa; } \\
\text { Justificativas de âmbito: social, tecnológico, econômico, } \\
\text { ambiental e científica; }\end{array}$ \\
\hline & $\begin{array}{l}\text { Registro e breve descrição do problema; } \\
\text { Objetivos (Geral e Específicos); } \\
\text { Apresentação das questões de pesquisa; } \\
\text { Organograma da pesquisa; }\end{array}$ \\
\hline \multirow{4}{*}{$\begin{array}{l}\text { Detalhamento } r \\
\text { subdivisão da segunda } \\
\text { etapa }\end{array}$} & Compilação de artigos para leitura; \\
\hline & Filtragem de conteúdo a partir das leituras; \\
\hline & Separar por temas chaves os conteúdos do referencial; \\
\hline & Construir o referencial teórico. \\
\hline \multirow{3}{*}{$\begin{array}{l}\text { Detalhamento } r \\
\text { subdivisão da terceira } \\
\text { etapa }\end{array}$} & Criação de pesquisa online; \\
\hline & Compilação de dados (analítica); \\
\hline & Definição de estratégias e resultados; \\
\hline $\begin{array}{l}\text { - Pesquisa de campo } \\
\text { (analítica) e resultados }\end{array}$ & Finalização escrita do artigo. \\
\hline
\end{tabular}

Fonte: As autoras (2021)

O processo de análise e interpretação dos dados desta pesquisa varia em função dos diferentes aspectos que a estruturam, e seguem os passos descritos pela figura 03, de acordo com Carvalho e Vergara (2002), que sugere uma sequência orientada a interpretação dos dados coletados.

Figura 03: Organização do conceito processo de análise e interpretação dos dados

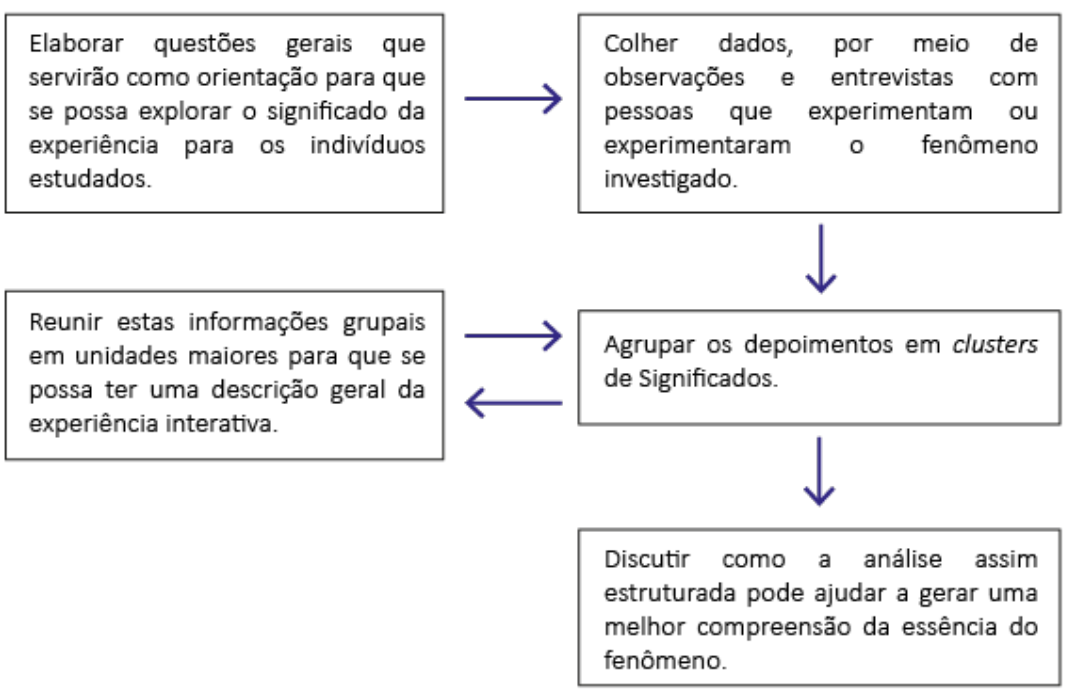

Fonte: Adaptado de Carvalho e Vergara, 2002, p. 84

Estas análises servirão de norte para entender a experiência do usuário, desde o ponto de vista das interações sociais e técnicas, cujos atributos de design participativo serão considerados como estratégicos para possíveis inovações na interface gráfica das redes sociais estudadas.

Foram feitos mapeamentos da percepção do usuário a partir dos questionamentos, buscando propostas que possam melhorar sua experiência e tornar as ferramentas sócio aplicadas um pouco mais eficientes. 


\section{Discussão dOS RESULTADOS}

\subsection{ENTREVISTA VIA GOOGLE FORMS COM USUÁRIOS DE REDES SOCIAIS}

Foi desenvolvido de forma conjunta pelo grupo dessa pesquisa, um questionário para ser aplicado via Google Formulários com usuários de redes sociais. A partir do entendimento sobre algumas evidências, pode-se apontar possíveis disfunções sistêmicas que envolvam a interação do usuário em relação a sua percepção e resposta. A amostra de participantes dessa pesquisa envolveu 207 respondentes sobre a qual se verificou algumas informações essenciais para caracterizar o perfil social dessa amostra. Essa amostragem é composta por pessoas de faixas etárias diferentes, variando entre menores de 18 anos e maiores de 55 anos. Contudo, o público que mais se destacou dentre eles se encontra na faixa entre os 18 e 24 anos, conforme pode ser observado pelo gráfico 01.

Gráfico 1: Faixa etária dos respondentes

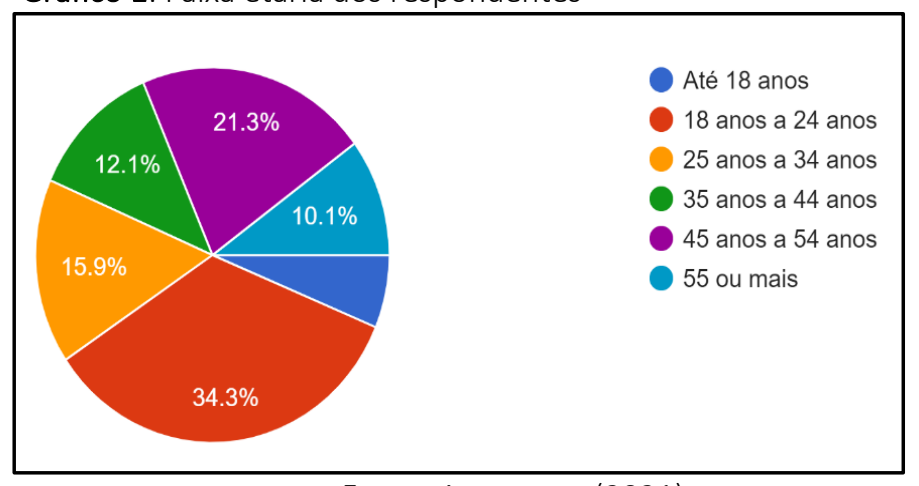

Fonte: As autoras (2021)

Além da idade também foi importante identificar o grau de escolaridade dos participantes, uma vez que, ao se conhecer o meio em que este participante transita e se conecta socialmente, podem surgir a sinalização de elementos informacionais oriundos das influências que este exerce sobre seu meio, assim como é influenciado. O gráfico 02 mostra que a maioria dos participantes se enquadram entre possuir o ensino superior incompleto e completo.

Gráfico 2: Escolaridade dos respondentes

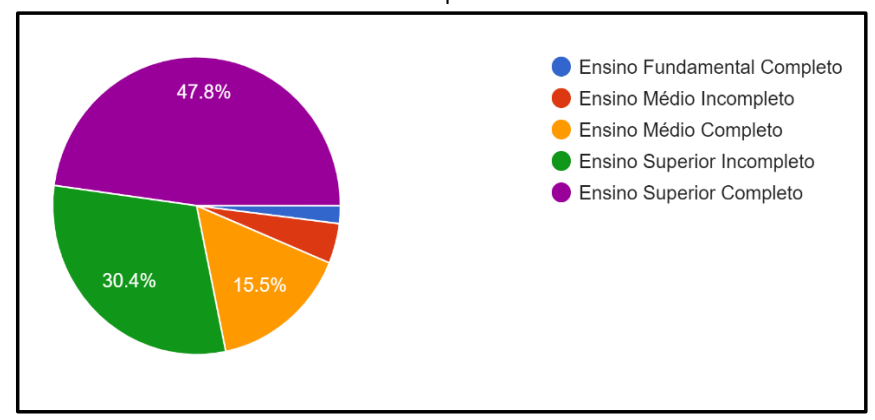

Fonte: As autoras (2021)

Em relação à terceira pergunta do questionário realizado, conforme o gráfico 03 , foi possível perceber que a rede social Instagram se destaca em relação às demais, sendo então a mais utilizada pelos participantes, seguida pelas redes Twitter e Facebook. A ênfase no Instagram denota a crescente utilização desta rede, o que pode indicar uma preferência dos usuários por plataformas mais visuais. 
Gráfico 3: Redes sociais mais utilizadas pelos participantes

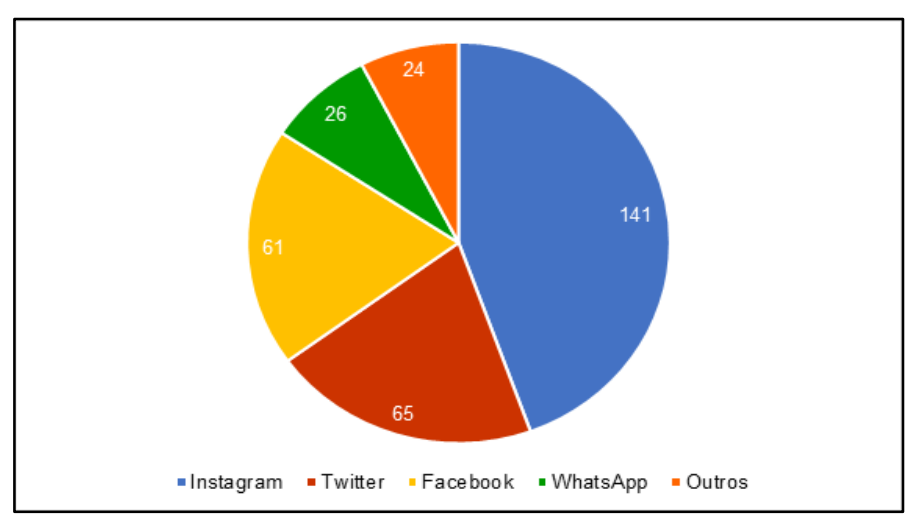

Fonte: As autoras (2021)

Em relação a pergunta sobre dispositivos tecnológicos mais utilizados para acessar as redes, por meio do gráfico 04, constata-se que 190 dos 207 participantes optaram primordialmente pelos dispositivos móveis, ao passo que apenas 34 do total preferem o computador. Partindo deste pressuposto, os designers das redes sociais podem tomar esse elemento como parâmetro para desenvolver projetos de interfaces mais versáteis, prezando por uma experiência do usuário mais positiva.

Gráfico 4: Dispositivos pelos quais as redes sociais são mais acessadas

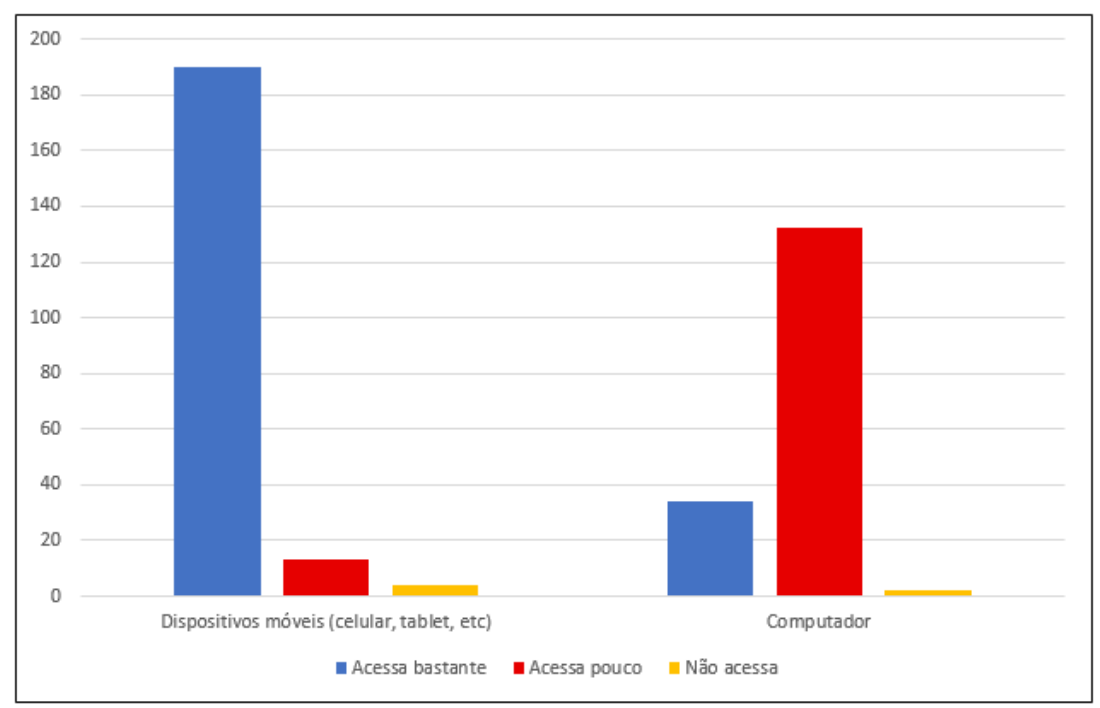

Fonte: As autoras (2021)

O gráfico 05 apresenta a frequência com a qual os usuários realizam atualizações dos aplicativos das redes sociais. Embora os participantes naveguem principalmente por meio de seus respectivos aplicativos móveis, menos da metade afirma mantê-los sempre atualizados. Esta informação apresenta um dado interessante, já que as atualizações contribuem para o bom funcionamento dos aplicativos, pois corrigem falhas e problemas, além de acrescentar novos recursos. É necessário, dessa forma, que os desenvolvedores reforcem a importância das atualizações para seus usuários. 
Gráfico 5: Frequência de atualização dos aplicativos das redes sociais

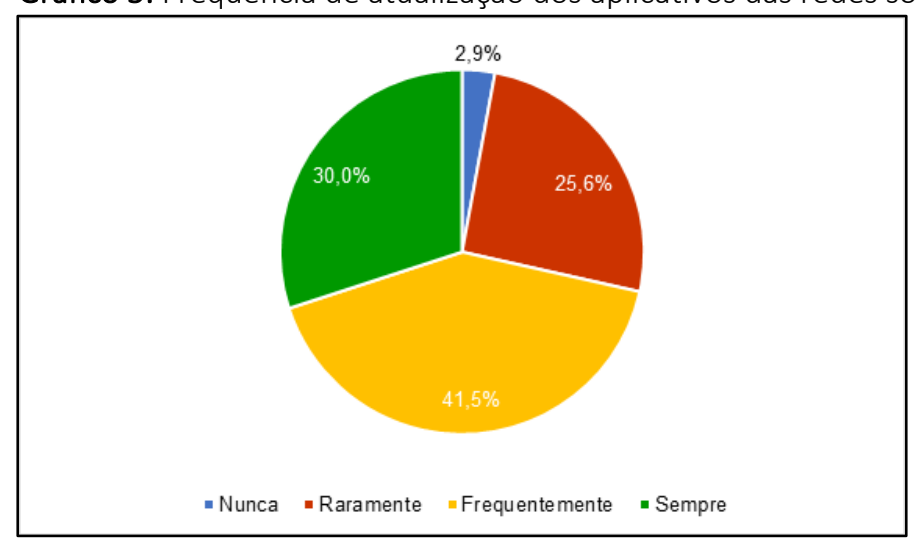

Fonte: As autoras (2021)

Conforme o gráfico 06, quanto ao tempo de uso das redes sociais, apenas $13,5 \%$ dos usuários consomem as redes por cerca de 1 hora, enquanto mais da metade informou que navegam entre 1 e 4 horas por dia. Esta média diária, cada vez mais crescente, pode sugerir que os designers estão preocupados em atender às necessidades de seus usuários, que em resposta, permanecem mais tempo usufruindo dos conteúdos apresentados a eles.

Gráfico 6: Tempo diário de utilização das redes sociais

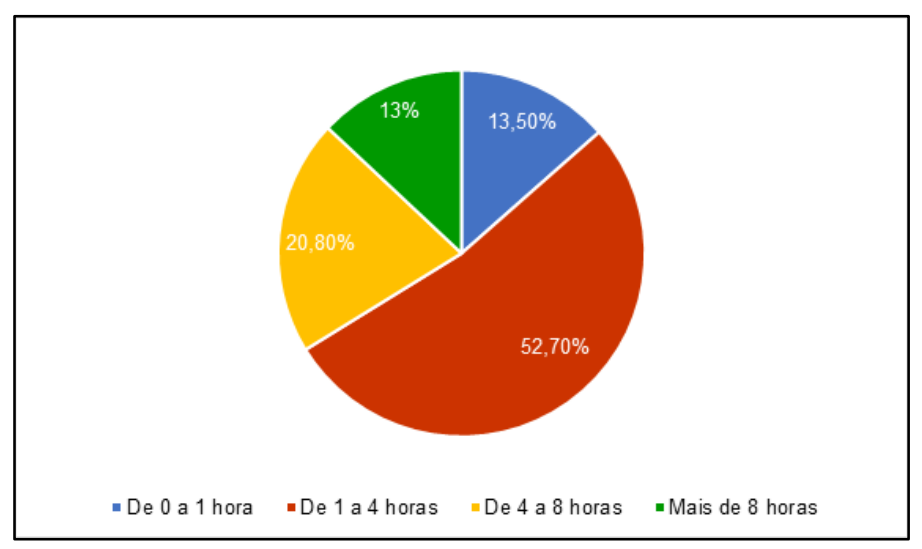

Fonte: As autoras (2021)

Conforme o gráfico 07, com relação aos motivos que levam os participantes a utilizar sua rede social de preferência, 76,8\% afirmam usar por mero entretenimento, como forma de lazer. Porém, ainda $74,9 \%$ dessas pessoas também aproveitam para se atualizar de notícias. Pode-se afirmar, portanto, que essas são as duas principais funcionalidades das redes, além da interação entre usuários. Esse feedback se torna interessante para os designers no sentido de indicar quais otimizações podem ser feitas para atender aos usuários. 
Gráfico 7: Motivação para o uso das redes sociais

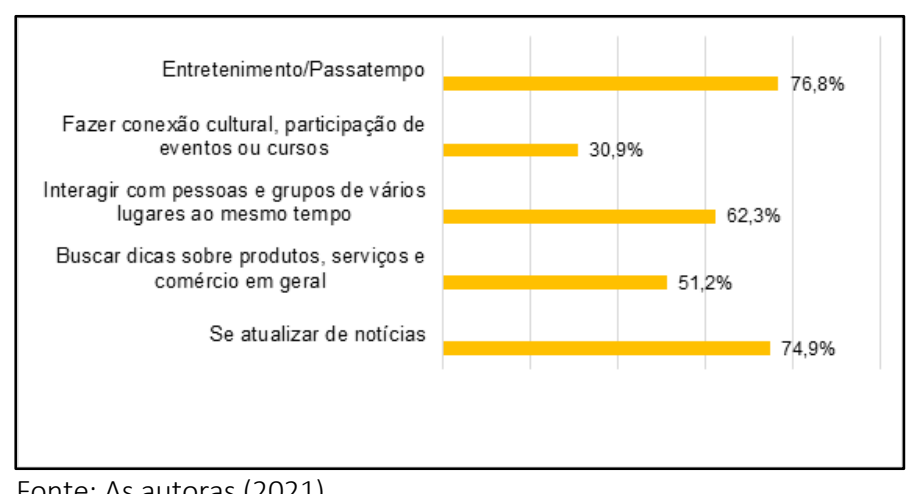

As redes sociais foram desenvolvidas com o intuito de aproximar e gerar uma interação entre os usuários. Contudo se observou que com as constantes atualizações surgiram variados focos de publicações. A partir disso foi levantada a questão sobre a motivação de utilização das redes sociais por parte destes usuários. Por meio do gráfico 08 , nota-se que metade dos entrevistados acreditam que a variedade de conteúdo é uma característica que influencia positivamente no uso de uma rede social, enquanto apenas 2,9\% afirmam utilizar as redes para marketing pessoal.

Gráfico 8: Principais motivações para uso das redes sociais

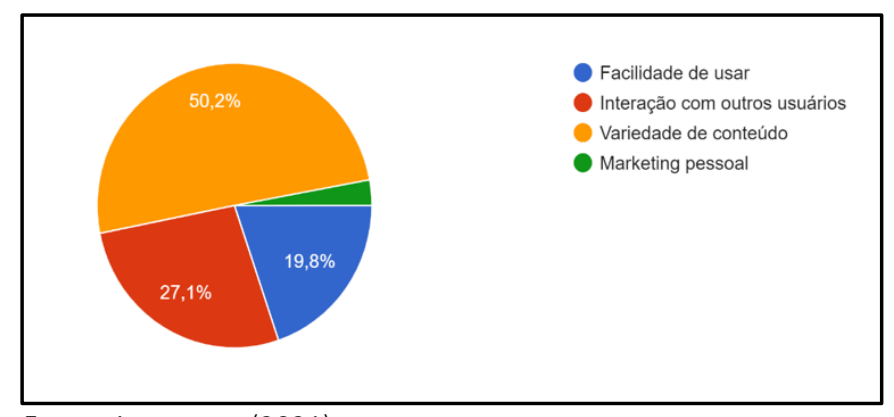

Fonte: As autoras (2021)

O gráfico 09 apresenta a resposta dos usuários em relação a sua forma de participação, verificando que $56 \%$ dos respondentes dizem consumir e compartilhar conteúdo de outros usuários, além de interagir de forma ativa, enquanto apenas 13\% somente consome conteúdo. Esse dado traz consigo uma importante informação, pois a interação e troca constante de informação permite a conceituação de um contexto de proatividade, indicando que grande parte dos usuários interage de forma participativa.

Gráfico 9: Forma de participação dos respondentes nas redes sociais

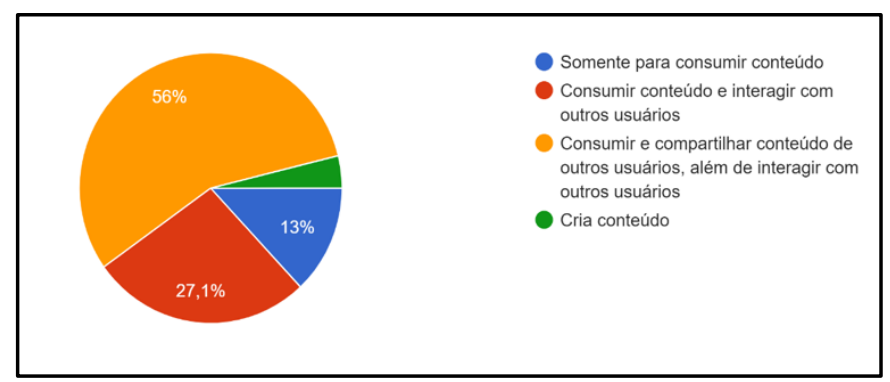

Fonte: As autoras (2021)

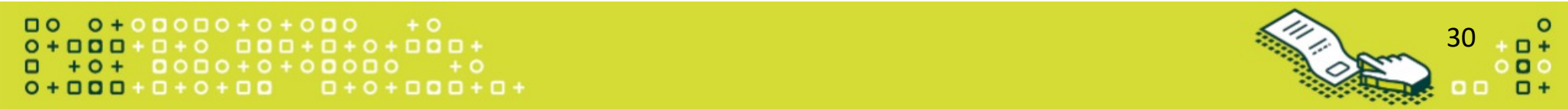




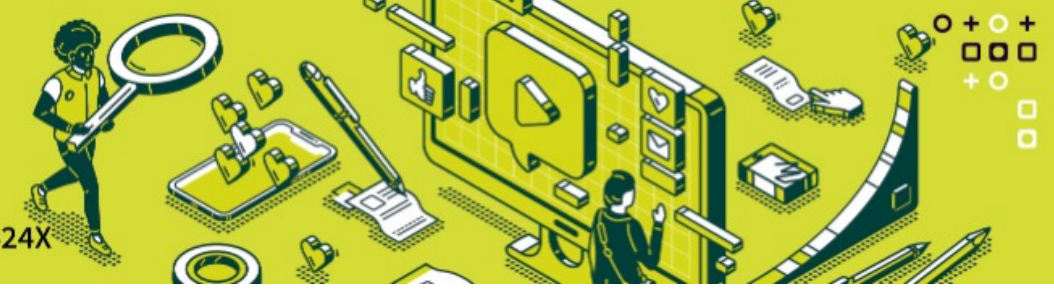

Em relação ao gráfico 10, sobre o conhecimento das funcionalidades das redes sociais, mais da metade dos participantes se considera bom, enquanto apenas 1,9\% se considera ruim. Percebese então que os usuários demonstram uma facilidade ao utilizar as redes sociais, evidenciando a existência de aspectos operacionais já conhecidos em relação a um aprendizado cognitivo de funções de uso destes sistemas.

Gráfico 10: Nível de conhecimento sobre as funções dos aplicativos das redes sociais

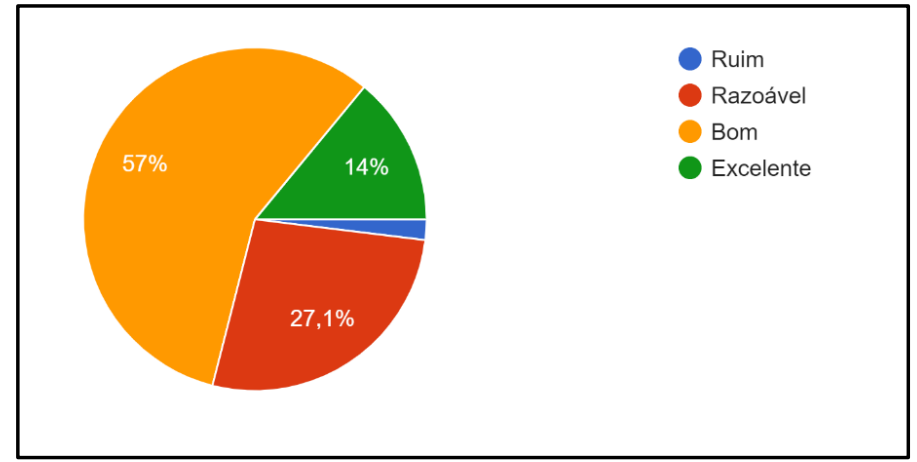

Fonte: As autoras (2021)

O gráfico 11 questiona a opinião dos entrevistados em relação a importância de um tutorial básico sobre a utilização do aplicativo. Neste sentido $64,7 \%$ dos entrevistados concordam que é necessário, enquanto apenas $9,7 \%$ deles não acham necessário. Portanto, chega-se à conclusão de que o desenvolvimento de instruções sobre o funcionamento deste tipo de aplicativo é fundamental para um bom funcionamento e uma boa experiência dos usuários.

Gráfico 11: Necessidade de tutorial introdutório de uso dos aplicativos das redes sociais

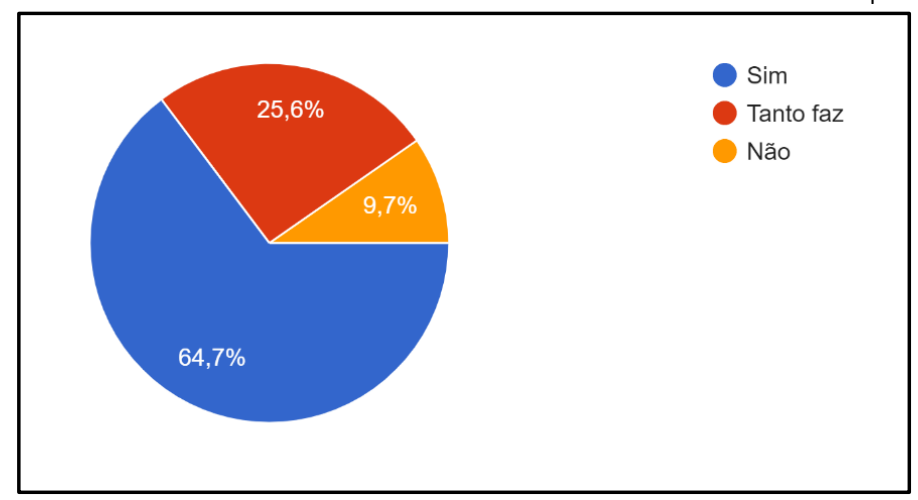

Fonte: As autoras (2021)

Em relação aos aspectos estruturais e funcionais das redes sociais preferidas pelos respondentes, o gráfico 12 apresenta a opinião deles sobre a usabilidade dos ícones dos aplicativos Instagram, Twitter e Facebook, no qual apontaram uma resposta positiva ou negativa para cada.

Todos os aplicativos obtiveram mais respostas positivas, embora a diferença entre respostas para o Facebook tenha sido menor. Isso traz um importante parâmetro, pois interfaces minimalistas, como as do Instagram e do Twitter, mostraram-se mais fáceis de navegar, enquanto interfaces mais complexas e com muitos ícones, como a do Facebook, podem causar desconforto e confusão ao serem utilizadas. 
Gráfico 12: Posicionamento dos ícones de utilização dos aplicativos Fonte: As autoras (2021)

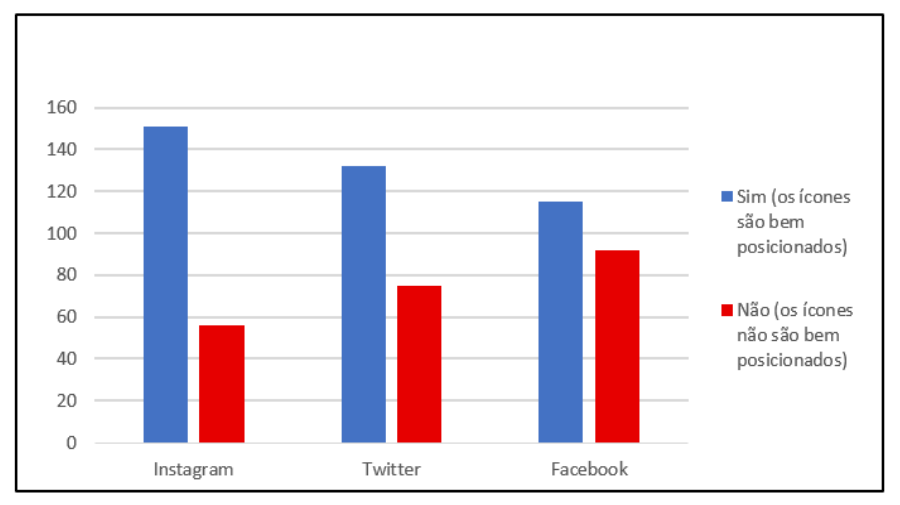

O gráfico 13 apresenta a resposta dos entrevistados referente a influência direta sobre o fluxo de interação e navegabilidade resultantes do posicionamento dos ícones das interfaces. Nesse sentido $87,4 \%$ dos respondentes afirmaram que a disposição dos elementos os influencia diretamente na interação e na navegação, demonstrando a essencialidade de um posicionamento ergonomicamente pensado e que se adeque as necessidades dos usuários.

Gráfico 13: Influência da disposição dos elementos na tela durante a interação com os aplicativos

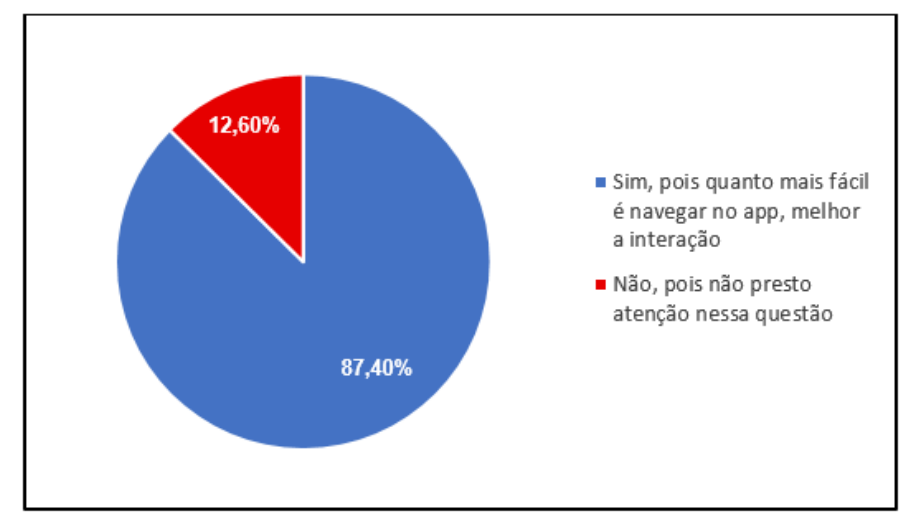

Fonte: As autoras (2021)

Quanto a facilidade de compreensão dos ícones das redes sociais, vide gráfico 14, embora a maioria dos entrevistados afirme que no geral os ícones são fáceis de compreender e de os associar a seus respectivos significados, não havendo conflito de percepção e entendimento, ainda 44,5\% demonstram-se confusos quanto a sua compreensão dos ícones.

Gráfico 14: Compreensão dos ícones utilizados pelos aplicativos para indicar ações e abas

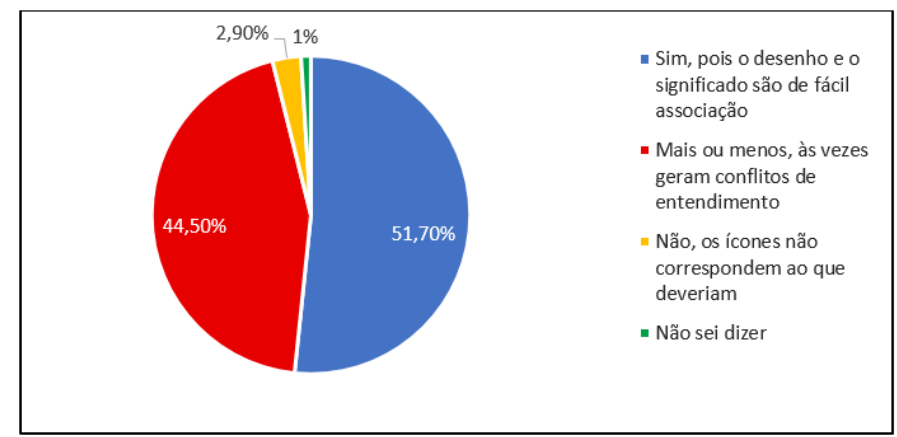

Fonte: As autoras (2021) 


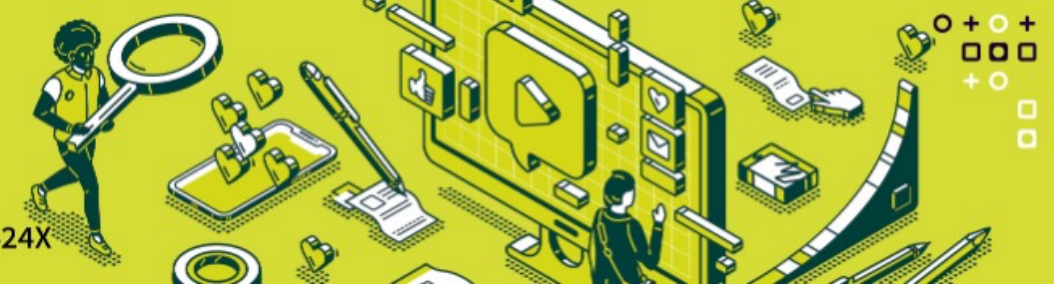

Em relação a influência dos fatores estéticos, como cores, fontes e ícones, como mostrado no gráfico 15, 87,9\% dos entrevistados afirmaram que estes elementos afetam as suas experiências, tanto de forma positiva quanto negativa. Portanto, esse dado expressa a importância da qualidade estética da interface. Embora 12,1\% afirmarem não reparar muito na estética das interfaces e não sentirem sua experiência afetada, deve-se aprofundar esta questão, uma vez que parte dessas pessoas pode sofrer influência por esses fatores sem perceber.

Gráfico 15: Influência dos fatores estéticos na experiência do usuário

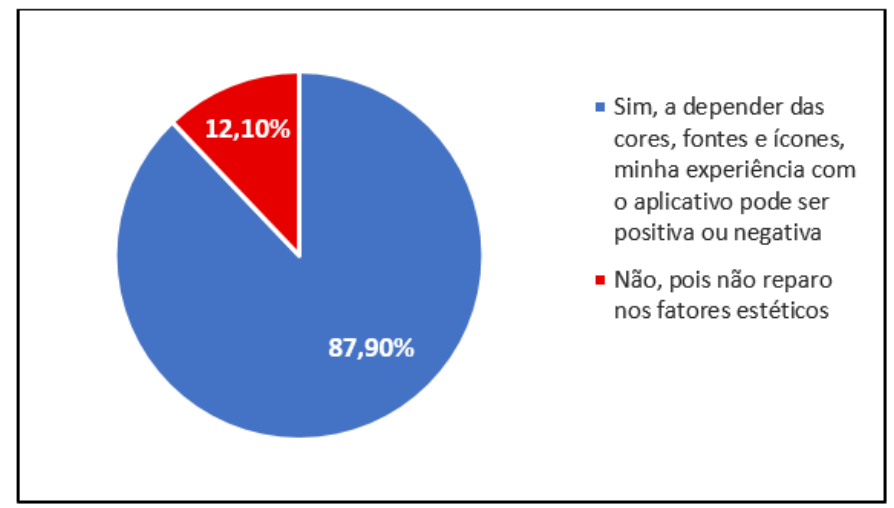

Fonte: As autoras (2021)

O gráfico 16 apresenta um balanço equilibrado das opiniões sobre o uso das redes sociais como meio de divulgação comercial. Este resultado pode significar que a receptividade do marketing digital nesse meio é um divisor de águas. Portanto esta questão merece um estudo posterior mais específico.

Gráfico 16: Opiniões sobre o uso das redes sociais como divulgação comercial

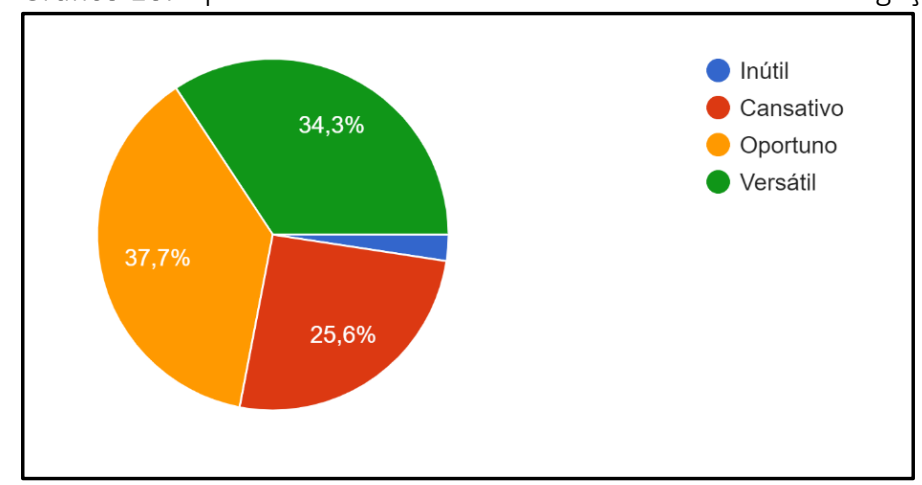

Fonte: As autoras (2021)

Em relação ao feedback dado pelos aplicativos em relação às demandas feitas pelos usuários, como denúncias e reclamações, observa-se pelo gráfico 17 um resultado dividido, com 52,2\% de respostas positivas e $47,8 \%$ de respostas que consideram ineficiente a ação desses aplicativos. Isso demonstra a necessidade de melhorar a comunicação entre as redes sociais e seu público, assim como a tomada de providências em relação aos problemas encontrados pelos usuários durante a navegação pelos aplicativos. 
Gráfico 17: Feedback dos aplicativos em relação às demandas dos usuários

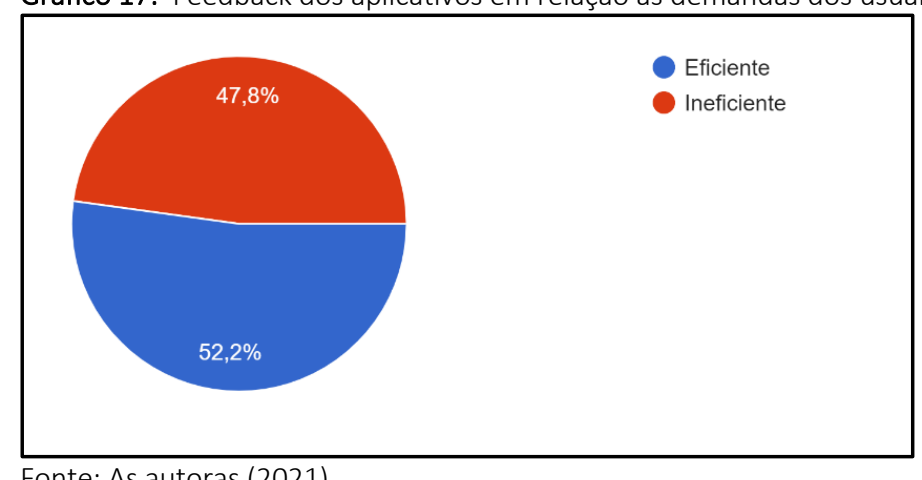

Fonte: As autoras (2021)

Em se tratando de uma análise sobre o estudo de caso, a interpretação dos dados coletados, feita por meio de entrevista a um determinado grupo amostral, caracteriza-se por um esquema não rígido. Além disso, os elementos envolvidos compõem blocos conceituais que visam gerar, por meio dos resultados, requisitos e parâmetros considerados essenciais a projetação e melhorias dos elementos comunicacionais. As entrevistas realizadas com os usuários foram de suma importância para evidenciar algumas disfunções e assim definir recomendações e requisitos para posterior implementação.

\section{Resultados finais E CONCLUSÃo}

Com base nos dados obtidos através do questionário aplicado, orientado pela técnica de imersão sugerida pelo Design Thinking, foi possível traçar o perfil do usuário das redes sociais, considerando os aspectos positivos e negativos a partir da percepção deles. Foi, então, criada uma persona, representação fictícia desse perfil traçado, que seria o público-alvo das possíveis melhorias propostas durante as fases seguintes do Design Thinking, como pode-se ver na figura 04:

Figura 04: Persona criada a partir dos dados coletados

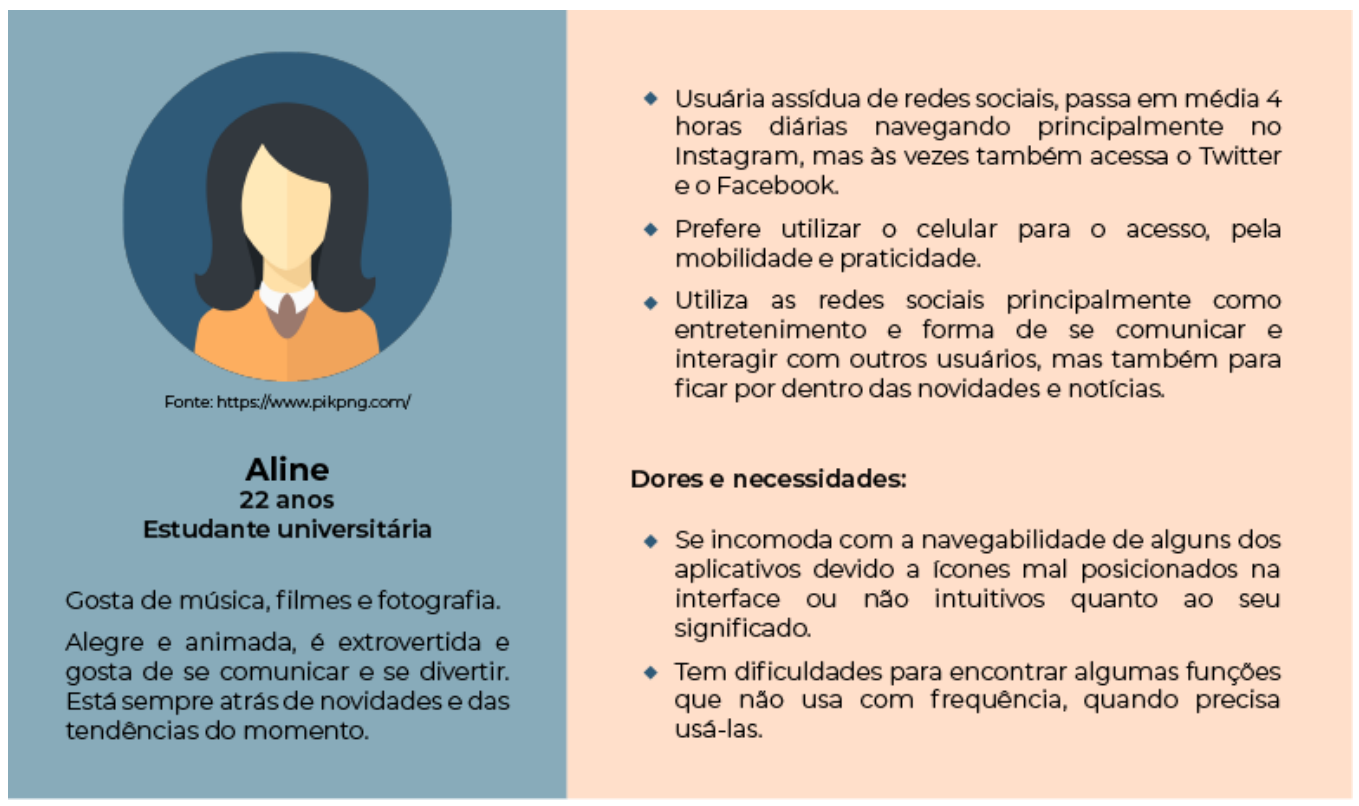

Fonte: As autoras (2021)

É possível, então, estabelecer requisitos e parâmetros para atender à necessidade dos usuários, representados pela persona, considerando a gama de experiência apresentada. De tal forma, é

Usuária assidua de redes sociais, passa em média 4 horas diarias navegando principalmente no e o Facebook.

Prefere utilizar o celular para o acesso, pela ade e praticidade. entretenimento interagir com outros usuários, mas também para

ores e necessidades:

Se incomoda com a navegabilidade de alguns dos aplicativos devido a icones mal posicionados na interface ou nåo intuitivos quanto ao seu 


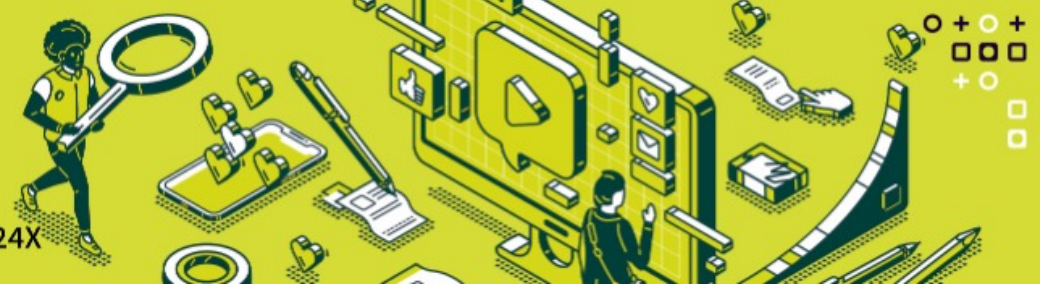

preciso salientar que a elaboração de tais requisitos e parâmetros são dados que irão colaborar na execução de soluções posteriores em estudos futuros.

A partir desse estudo também foi possível identificar elementos comunicacionais que exercem influência sobre a experiência do usuário das redes sociais. Neste sentido, o quadro 2 apresenta uma relação entre requisitos e parâmetros projetuais que poderão orientar estratégias de criação, otimização e inovação dentre esses elementos.

Quadro 2: Requisitos e parâmetros

\begin{tabular}{|c|c|c|}
\hline & Requisitos & Parâmetros \\
\hline 1 & Perfil sociocultural. & Jovens e adultos estudantes ou graduados; \\
\hline 2 & $\begin{array}{l}\text { Características marcantes da rede } \\
\text { social. }\end{array}$ & Interfaces de contexto mais visual gráfica que textual; \\
\hline 3 & tecnológicos & $\begin{array}{l}\text { Dispositivos móveis como os celulares e tablets, indicando } \\
\text { versatilidade; }\end{array}$ \\
\hline 4 & $\begin{array}{l}\text { Importância de atualização dos } \\
\text { sistemas envolvidos. }\end{array}$ & $\begin{array}{l}\text { Desenvolver elementos comunicacionais que reforcem a } \\
\text { importância de atualização dos sistemas; }\end{array}$ \\
\hline 5 & comunicacionais & $\begin{array}{l}\text { Considerar as funções estéticas e funções de navegabilidade, } \\
\text { fluidez, leiturabilidade e de cognição; }\end{array}$ \\
\hline 6 & Manual de utilização & Exibição de orientações por meio de um tutorial; \\
\hline 7 & Aspectos sociais de interação & $\begin{array}{l}\text { Evidenciar a versatilidade de interação, permitindo ao } \\
\text { usuário escolher como interagir; }\end{array}$ \\
\hline 8 & Feedback do sistema & $\begin{array}{l}\text { Otimizar o feedback do sistema para considerar a experiência } \\
\text { do usuário. }\end{array}$ \\
\hline
\end{tabular}

Fonte: As autoras (2021)

Os requisitos e parâmetros podem ser o ponto de partida para as próximas fases do estudo, uma vez que podem ser considerados elementares para a etapa de criação e experimentação de forma aplicada.

\section{REFERÊNCIAS}

AGNER, L. et al. Design de interação no jornalismo para tablets: avaliando interfaces gestuais em um aplicativo de notícias. COMUM, Rio de Janeiro, v.15, n.34, p 140-159, jul./dez. 2013.

CAVALCANTI, C. M. C. Design Thinking como metodologia de pesquisa para concepção de um ambiente virtual de aprendizagem centrado no usuário. 2014.

ELLWANGER, C. Design de Interação, Design Experiencial e Design Thinking: A tríade que permeia o escopo de desenvolvimento de sistemas computacionais interativos. 2013. Pág. $799-802$.

FONSECA, L. M. M. et al. Design emocional e as suas contribuições para a tecnologia educacional digital na saúde e na enfermagem: revisão integrativa. Revista de Enfermagem Referência, LOCAL, vol. IV, n. ${ }^{\circ}$ 6, p.141-149, 2015.

GONZATTO, R. F. Design de interação e a Amanualidade em Álvaro Vieira Pinto. Curitiba: Programa de Pós-Graduação em Tecnologia/Universidade Tecnológica Federal do Paraná, Dissertação de mestrado, 2014.2 Disponível em: http://repositorio.utfpr.edu.br/ispui/handle/1/808.

GÜNTHER, A. TRISKA, R. Informação e experiência nas redes sociais. Revista (online). Rio de Janeiro: v v. 21 | n. 1 [2013], p. $01-22$.

HACK, R. J.; SANTOS, J. A. dos. Influência do design emocional na interação homem/computador, 2010. 
POLINO, C. de A., Redes Sociais Comunicacionais: Análise dos Elementos que Envolvem os Usuários do/com o Twitter. In: Congresso de Ciências da Comunicação na Região Sul, XVI, 2015, Joinville.

ROSA, J; MATOS, E. Anais do XXVI Simpósio Brasileiro de Informática na Educação (SBIE 2015) Salvador.

SANTOS, B. C. S. A importância do design para tornar as redes sociais mais interativas. Texto livre: linguagem e tecnologia, Belo Horizontem v.6, n.1, p.150-164, 2013. Disponível em: http://periodicos.letras.ufmg.br/index.php/textolivre.

SILVA, C. A. Design emocional: afetos positivos e negativos nas interações com ambientes web. 2011. Dissertação (Mestrado em Design e Expressão Gráfica) - Departamento de Expressão Gráfica, Universidade Federal de Santa Catarina, Florianópolis, 2011. Disponível em: https://repositorio.ufsc.br/xmlui/handle/123456789/96089

SIMÃO, L. M. F. Design de interação como diretriz de formação do profissional de interface. In: Congresso Latino-americano de Interação Humano-Computador, 2003, Rio de Janeiro. Workshop sobre Interdisciplinaridade em IHC, Rio de Janeiro, 2003, p. 16-17.

SIMÕES, F. A.; VALENTE, J. A. Design emocional e significado: a experiência do usuário no processo criativo de Novas Mídias, 2018.

SUWA, M., TVERSKY, B. What do architects and students perceive in their design sketches? A protocol analysis. Design Studies. Oxford: Elsevier Science Ltd., v. 18, p. 385-403, 1997.

VIANNA, M. et al. Design thinking: inovações em negócios. Rio de Janeiro; MJV Press, 2012.

This research, carried out within the scope of the Samsung-UFAM Project for Education and Research (SUPER), according to Article 48 of Decree $n$ ㅇ 6.008/2006(SUFRAMA), was funded by Samsung Electronics of Amazonia Ltda., under the terms of Federal Law no 8.387/1991, through agreement 001/2020, signed with Federal University of Amazonas and FAEPI, Brazil. 